\title{
Perceptions of joint pain and feeling well in older people who reported being healthy: a qualitative study
}

\author{
Janet Grime, Jane C Richardson and Bio Nio Ong
}

\author{
ABSTRACT

\section{Background} \\ Older people often view osteoarthritis as a part of \\ normal ageing and see themselves as healthy despite \\ painful joints. Professionals have mixed views about \\ this. One concern is that seeing osteoarthritis as a \\ result of 'wear and tear' leads to restricting exercise in \\ order to avoid further wear. \\ Aim \\ To explore lay perceptions of wellness and joint pain, \\ and their implications for consulting healthcare \\ professionals and taking exercise. \\ Design of study \\ Qualitative, longitudinal study`.

\section{Setting} \\ General practice in the North Midlands. \\ Method \\ Semi-structured interviews with 27 older people who \\ reported a joint problem but rated themselves as \\ healthy. Diary sheets were sent for 11 consecutive \\ months to record changes in health and \\ circumstances. Thematic data analysis was facilitated \\ by NVivo 8 . \\ Results \\ A key element of wellness was being able to continue \\ with everyday roles and activities. 'Wear and tear' was \\ used to categorise arthritis that is a normal part of old \\ age. New joint symptoms that came on suddenly and \\ severely were not necessarily attributed to 'wear and \\ tear' arthritis, and were likely to lead to a professional \\ consultation. Physical activity was not restricted to \\ prevent further wear of affected joint(s). Keeping joints \\ mobile was important in order to maintain \\ independence.

\section{Conclusion} \\ Professionals should explore patients' ideas and \\ concerns about their joint problem, in order to \\ individually tailor explanations and advice. Patients are \\ likely to be receptive to recommendations that promote \\ independence, but advice needs to be set into \\ patients' existing ways of living and coping with joint \\ pain.

\section{Keywords} \\ Health; joint pain; elderly; osteoarthritis; primary care.
}

\section{INTRODUCTION}

Joint pain is widespread in people after middle age, and osteoarthritis is the most common cause of this symptom. Most older people with chronic peripheral joint pain do not consult a doctor, ${ }^{1}$ a major reason being that joint pain and stiffness are seen as an inevitable part of ageing for which the doctor can do little., ${ }^{2,3}$

Paradoxically, from a biomedical perspective, osteoarthritis has been transformed from a natural part of ageing - the result of 'wear and tear' and of little interest to clinicians - to a medical condition, which has an active disease process. ${ }^{4}$ In spite of this, there are conflicting views among healthcare professionals about the advantage of medicalising joint pain in older people. Dieppe argues that most people with osteoarthritis are not seriously affected, and in only a few will joint damage progress. ${ }^{5} \mathrm{He}$ questions the benefit of seeing milder cases of osteoarthritis as a medical problem. Woolf, on the other hand, advises that not only those with early signs of a musculoskeletal condition but also those who are deemed to be at risk should receive appropriate healthcare interventions. ${ }^{6}$

In practice, older people who consult with chronic pain often say that their doctor attributed joint pain to growing old, ${ }^{7}$ and advised them to put up with it. ${ }^{3}$ Wear and tear - the wearing away of joints with use

J Grime, MMedSci, research fellow; JC Richardson, $P h D$, senior lecturer in health services research; $B N$ Ong, $P h D$, professor of health services research, Keele University, Arthritis Research UK Primary Care Centre, Keele.

Address for correspondence

Mrs Janet Grime, Keele University, Arthritis Research UK

Primary Care Centre, Keele, Staffs,

ST5 5BG. Email: j.c.grime@keele.ac.uk

Submitted: 14 September 2009; Editor's response: 23 November 2009; final acceptance: 5 January 2010.

(C)British Journal of General Practice 2010; 60: 597-603.

DOI: 10.3399/bjgp10X515106 


\section{How this fits in}

There are concerns that older people normalise osteoarthritis by seeing it as wear and tear; as a consequence, they do not seek medical help and they limit exercise in order to prevent further wear of the affected joint. This study found that older people were able to distinguish between 'wear and tear-type' joint pain and other joint pain that they did not consider to be normal for their age. They were likely to consult with the latter type of joint pain. Responders did not limit physical activity to prevent further wear of the joint; on the contrary, keeping joints mobile was considered essential for maintaining independence and a sense of wellness. responders who had reported osteoarthritis/pain in peripheral joints and who had agreed to further contact were assessed, in order to find responders from across the age range 50 to 90 years, who rated their health as good/very good, or as fair if they had moderate/severe pain and physical limitations. Those who reported no health problem and/or no limitation and/or mild pain were excluded. From the 60 people approached, 27 agreed to take part. In only two instances were reasons given for declining to participate - bereavement and being very elderly (90 years).

An in-depth interview was carried out at baseline, using the life-grid approach. ${ }^{10}$ Responders talked about family, work, leisure, and health throughout their life course. In addition, they were asked about their current daily life, the impact of joint pain, how they saw their present and future health (and why), their use of health and social services, and any advice they might have for others with similar joint pain/osteoarthritis in order to stay well and healthy. Interviews were digitally recorded and fully transcribed.

Each responder was sent a monthly diary sheet for 11 months following the interview. The sheet asked about changes to their health (for example, whether they were feeling more or less well than normal), their problem joint(s), and personal circumstances that affected how they were coping or felt in themselves. A thematic analysis was carried out. Using the qualitative software package NVivo 8, a coding framework was drawn up and refined following independent coding. The authors then met to organise the codes into themes, which categorised the data so that conceptual analysis could be developed.

\section{RESULTS}

Twenty seven people aged between 56 and 87 years agreed to participate in the study (Table 1). Five withdrew or were not contactable after the first interview, and one withdrew after 6 months because her husband was seriously ill. Most were born within a few miles of their current address. Nearly all had worked, or were working, in local manufacturing or service industries. Six had undertaken higher education.

Despite purposefully sampling from a cohort study to include only those who had long-standing peripheral joint pain/osteoarthritis of at least medium intensity, the baseline interview revealed that responders reported a range of conditions. These were categorised as shown in Table 2.

\section{Ageing and perceptions of wellness}

Responders often assessed their health in terms of 
Table 2. Type of joint problem (as described by responder).

\begin{tabular}{llccc} 
Musculoskeletal problem & Age, years & Males & Females & Total \\
\hline Uncertain diagnosis & $50 \mathrm{~s}$ & 1 & - & 1 \\
\hline Immune disease/childhood problem & $60 \mathrm{~s}$ and $70 \mathrm{~s}$ & - & 3 & 3 \\
\hline Sudden/recent 'osteoarthritis' & $60 \mathrm{~s}, 70 \mathrm{~s}$, and $80 \mathrm{~s}$ & 2 & 2 & 4 \\
\hline Gradual onset from middle age & $50 \mathrm{~s}, 60 \mathrm{~s}$ and 70s & 5 & 4 & 9 \\
\hline Very minor joint problem & $60 \mathrm{~s}$ and 80s & 1 & 1 & 2 \\
\hline Osteoarthritis + motor nerve problem & $70 \mathrm{~s}$ & 2 & - & 2 \\
\hline Long-standing back problem & $60 \mathrm{~s}$ and 70s & - & 4 & 4 \\
\hline Trauma & $70 \mathrm{~s}$ & 1 & 1 & 2 \\
\hline
\end{tabular}

what might be expected for someone of their age:

'At the moment, I class myself as very healthy for my age. I feel a lot younger than I actually am, and hopefully act a lot younger.' (Anne, mid-60s)

Physical decline was seen as a normal part of growing older and as such did not necessarily interfere with a self-perception of being well. Being mentally alert and not having memory problems were considered more important:

'I feel well, yes. I don't know if I give the impression but I feel that my mind is clear, my memory's okay. So, my body is not as good as it was, I'm aware of that, but all in all, putting everything, you know, into perspective, being 80 next month, I feel pretty good.' (Lewis, late 70s)

'Thankfully, I'm mentally alert. Until these ankles flared up in May, I was, for my age, I would say I was very active.' (Miles, mid-80s)

Several people distinguished between how they felt inside their bodies and how they might outwardly appear to others, or even to themselves when they looked in a mirror:

'You know you look older and people say you can tell you're getting older now and all this but you don't feel old in your mind, you still feel about 18, 20 odd. Don't you?' (Peter, early 70s)

'If I didn't look at myself occasionally in the mirror, I wouldn't think that there was anything wrong.' (Arthur, late 70s, who is severely disabled)

Thus, even those who had a significantly changed external appearance were not necessarily conscious of it from day to day. Some used comparisons with others as an indicator of their degree of fitness and wellness:
'I mean, lots of people do slow down [physically] anyway, but I tend to think I'm 40!' (Gwen, early 70s)

Nevertheless, being independent - being able to get out and about, and fulfil everyday roles and activities - was also an important factor in enabling wellness. Being independent required a degree of physical capability, at least to be able to walk and/or drive:

Interviewer: 'What do you think it is that makes you say, "Yes, I'm a well person"?'

'Well, I suppose, it's because l've got my independence if you like - two eyes, two ears, which are a bit dicky, and two legs, which still go.' (Vida, late 70s)

'I think if you're walking and getting about a bit, you've got a good life haven't you?' (Keith, mid60s)

'If I've been in most of the day l'll just get in the car and I'll go sailing up the bypass. I might be only out of the house 10 minutes, quarter of an hour, but l've enjoyed that drive ...' (Lucy, mid-60s)

It was hard for these responders to imagine losing their mobility and feeling well. Thus, although the importance of the physical body for wellness was downplayed, a certain level of functioning was necessary.

\section{Normalising joint pain in later life}

Seeing joint pain as a normal part of ageing ran through the interviews like a leitmotif:

'And mine [joint pain] comes with age, so no, you just accept it.' (Kath, early 60s)

Wear and tear of the body was the main 
explanatory model:

'It's [osteoarthritis] wear and tear really isn't it? And probably, all the cleaning that I've done for like the last 18 years can't have helped much can it, so, you know, that's probably why it's come on ... I don't look at it as an illness or a disease.' (Carol, mid-50s, portfolio of domestic cleaning jobs over a 6-day week)

'But my thumbs started aching, I thought it was just old age, wear and tear ... it's just par for the course of living that is, the type of job you do.' (Phil, early 60s, lorry driver, previously a miner)

Wear and tear was used as a form of shorthand for normal bodily changes with ageing. Resulting joint pain was therefore also considered normal and not an illness. Wear and tear was not seen to arise from abusing the body but rather from virtuous use, such as physical labour.

\section{Consulting and type of joint pain}

All joint pain, however, was not automatically attributed to old age. The type of onset and severity of the pain led some responders to question if their joint pain was normal.

Miles, for example contrasted the cause of his back pain - 'the usual deterioration you find with old age' - with the pain in his ankles which came on suddenly and severely - 'when I was a boy I continually twisted my ankles, and many years ago my GP told me that I would suffer in later life'. He saw his ankle problem as a medical condition.

Brian summarised the significance of this lay nosological model for distinguishing between a pain that you have to live with, and a pain that is potentially a sign of a medical problem:

'... if it's a thing [a joint pain] that you know you've got to live with, then I think you've got to carry on regardless. But, like I say, if a sudden pain comes on then it is a warning, what's going on like, and you can see the doctor.' (Brian, early 60s)

A pain that was judged to be abnormal was likely to lead to a medical consultation.

A responder, who consulted with what she considered was not an age-related joint problem, found it difficult to accept a diagnosis of osteoarthritis. Beryl's knee had suddenly given way without any previous symptoms. She thought that her doctor, in attributing the cause to loss of cartilage through wear and tear, had misdiagnosed her with old age 'rheumatics', although she later accepted the diagnosis following a private consultation:
I said to the doctor [her GP who had diagnosed osteoarthritis], "How is it that it [knee] went like that [suddenly]?" ... I went to the Nuffield [private hospital] at first because nobody could convince me [that it was osteoarthritis] with it happening so quick. I wasn't convinced ... This nice doctor there [Nuffield], he put my legs up, he twisted my knees, he twisted my legs and he said did I want cortisone injections. I said, "No thank you". And he said, "I know they're [injections are] painful, it's better than the pain". I said, "Well, if you gave me cortisone, and this could go on forever, I'd have them, but not if it's going to come back every 3 months".' (Beryl, early 70s)

One important difference between the consultations was that the second doctor offered her painkillers, and so she felt her (abnormal) degree of pain was recognised. The physical examination of her knees also reassured her about the accuracy of the diagnosis. Towards the end of the study Beryl developed pain in her shoulders. It came on slowly and related to doing specific activities, such as ironing. She talked about this pain as arthritis:

'... there's no cure for arthritis, there's nothing they can do [medically] at all for it. The only thing they give you is perhaps rubbing stuff or painkillers ... I was going to make an appointment to go to the doctor's, but I know he'll say its arthritis.' (Beryl, early 70s)

She decided not to consult the doctor, but that she would mention it to the nurse when she next had a blood pressure check.

\section{The importance of physical activity for managing 'wear and tear' arthritis}

None of the responders limited physical activity in order to minimise further wear of their problem joint(s). On the contrary, several said they persevered with exercise as a form of therapy, even if their joint pain was worsening:

'My husband and I walk 2 miles every morning after breakfast; really to get my limbs going.' (Gwen, early 70s)

'Well, they've [knees] gradually got worse. But, I can still walk a fair distance. Last Sunday, for instance, I walked for an hour and 20 minutes.' (Robert, mid-70s)

'I do like working with my hands and if it's [finger] really, really painful any particular day, if I'm sitting, I'm moving it, I won't just let it set, I just 
move it about.' (Lucy, mid-60s)

Responders rarely said that medical advice was the reason for exercising. Two described how they took the initiative:

'I have asked [my GP] if I can go to the gym ... to get myself a bit fitter, because they said I was putting a lot of weight on. And nothing has come of it. She [GP] just laughed, and said, "You're all right. What do you expect? You've just gone through all that [had a lung removed], you're bound to have put a bit of weight put on".' (George, early 70s)

After being told that his age and general health meant he was unsuitable for knee replacement surgery, Miles explained how he had come to start a programme of knee exercises:

'Ever since my wife died, my daughter has adopted a very concerned attitude about my welfare [she lives a long distance away from me]. She, of her own volition, contacted the Arthritis Society and obtained their literature ... My impression is that the exercises are preventing my knee problem from getting worse.' (Miles, mid-80s)

When explaining their rationale for exercising joints affected by osteoarthritis, some responders drew on a different model from the wear and tear one used to normalise joint pain. They used a model of use it or lose it - using joints to prevent loss of function:

I'm willing to try anything that will help me stay mobile and I keep, you know, exercising because I think it's important. It's like anything, you've got to use it or you'll lose it.' (Jennifer, early 60s)

'[l stay healthy by] keeping mobile, because even though we're sort of disabled, it's a case of use it or lose it. If you want to keep your mobility you've got to move, even if you're in pain.' (Anne, mid-60s)

Arthur, for example, who had little mobility and lived in an adapted chair, refused the offer of a tape recorder to complete his monthly diary sheets, even though writing was onerous. He wanted to preserve what physical capabilities he had:

'Similarly, I make myself fasten my shirt buttons or make myself write because I do not want to lose these abilities.' (Arthur, late 70s)
The level of physical activity varied across responders, often according to how much it had been an interest over the life course:

I've always danced. My wife and I did ballroom dancing. I struggled at times but then you just go through the pain barrier and try to ignore it.' (Lewis, late 70s)

Some enjoyed walking, swimming, or other activities for their own sake, but others did not. The availability of gyms had led some to take up exercise more formally in later life, though not necessarily to continue with it:

'I've never done much actual sporty activities at all. I have joined a gym on various occasions but get very bored with that, you know ... I go quite enthusiastic [for] about 3 months and then boredom sets in and I tend to fall by the wayside, you know. So I'm not very good at committing to anything like that.' (Anne mid-60s)

However, many spoke of routine activities, such as housework, shopping or gardening, as exercise.

\section{DISCUSSION}

\section{Summary of main findings}

Study responders were selected because they considered themselves to be healthy despite having painful joints. They spoke of joint pain as a normal consequence of ageing and a result of wear and tear from virtuous use of their bodies over the life course. ${ }^{11}$ An impaired body did not necessarily compromise their sense of being well, as long as their brain functioned and they could be as independent as possible. Physical activity was not restricted in order to prevent further wear of the affected joint(s). The opposite was the case keeping stiff and painful joints mobile was considered important in order to conserve people's independence.

However, not all joint pain was attributed to osteoarthritis; for example, new joint symptoms that came on suddenly and severely were of concern. Responders were more likely to seek medical help in these circumstances.

\section{Strengths and limitations of the study}

The qualitative and longitudinal nature of the study enabled experiences that affected responders' sense of wellness to be explored in real time. Leaving decisions about follow-up contact to responders was a strength because it enabled investigation of the fluctuations experienced by people from month to month. It was also a limitation. There were several 
instances when responders summarised a change in the monthly diary sheet that seemed significant to the researchers, but they did not request contact, thus leaving the researchers unable to explore the significance of reported change.

\section{Comparison with existing literature}

Unsurprisingly, seeing osteoarthritis as a natural part of growing older, not as an illness, means older people manage their joint problem themselves rather than seek professional help. ${ }^{12,13}$ Turner et al examined the uptake of medical care for osteoarthritis in relation to lay beliefs. ${ }^{14}$ They argued that patients who saw osteoarthritis as a normal part of ageing were fatalistic and unable to interpret symptoms as a sign of ill-health, and as a consequence were reluctant to consult. However, several older people in the present study evaluated their joint pain according to its severity and type of onset, in order to establish if it was likely to be 'old age arthritis' - to be lived with, or something else not age related, with which it was appropriate to consult. Tulle found that veteran athletes created a typology of athletic injuries. ${ }^{15}$ The older runners distinguished between injuries caused by ageing (wear and tear or overuse of the knee for a long period of time) and those, such as muscle tears, that were not related to ageing. A GP advised one of Tulle's athletes to give up running and take up bowls, so he obtained private treatment for his 'non-agerelated knee problem' and quickly returned to running. In the present study, one responder, whose knee suddenly gave way, could not accept an osteoarthritis diagnosis. Her GP used the words 'wear and tear', and did not prescribe painkillers, so she felt that he had misdiagnosed her condition as minor and age related. Thus, a lack of congruency in the consultation between patient and healthcare professional over the nature of the joint problem being presented may result in diagnosis and advice being deemed inappropriate. ${ }^{2,16}$

Older people often prioritise maintaining independence over controlling pain, ${ }^{17,18}$ and conceptualise health as being able to carry out everyday tasks, including self-care..$^{9,19}$ There is conflicting evidence about lay perceptions of using exercise to care for joint pain. Ross et al, for example, found that exercise was favoured as part of a self-care strategy, ${ }^{13}$ and Lansbury found that it was not. ${ }^{20}$ One reason for the contradictory findings in the literature is probably terminological. Some researchers define exercise in a way that excludes everyday activities. ${ }^{8,21}$ Like those in the study of Ross et $a l,{ }^{13}$ the responders in the present study had a broad range of activities that they considered to be exercise, which included everyday tasks. Not all 'exercise' was undertaken as part of self-care; much of it was conducted in order to get on with normal life, and keep up valued roles and activities, including leisure pursuits. ${ }^{2,22}$

The wear and tear osteoarthritis model was not used as a biomechanical basis for taking decisions about exercise. Some responders invoked the model of 'use it or lose it', which, logically, is at odds with wear and tear.

\section{Implications for future research and clinical practice}

It is common for older people to normalise joint pain and not to consult a doctor. When people do consult they may have already worked up specific ideas and concerns about their joint pain. ${ }^{16}$ Patients should be encouraged to express these, so that clinical explanations and advice are individually tailored. While patients frequently see wear and tear as the cause of joint pain, practitioners should be careful how they use this as a diagnostic cause. A patient, for example, may be consulting because they do not think their joint pain is a result of wear and tear. Such a lack of congruency in the consultation may affect patient ideas on prognosis. ${ }^{23}$

Responders had developed complex and individualised ways of using physical activity to manage joint pain and get on with their everyday lives. ${ }^{22}$ They were receptive to suggestions that help maintain independence, such as the role of exercise. Exercise advice, though, needs to draw on patients' existing ways of managing, and to reflect personal abilities, preferences, and priorities. ${ }^{24}$ Motivational interviewing uses this kind of approach to support patient behaviour change. ${ }^{25}$

Future research could explore the views of older people who do not consider themselves to be healthy.

\section{Funding body}

This study was funded by the Economic and Social Research Council (reference number RES-000-22-2812).

\section{Ethical approval}

The study was approved by South Staffordshire Research Ethics Committee (reference number 08/H1203/52).

\section{Competing interests}

The authors have stated that there are none.

\section{Acknowledgements}

We would like to thank all those who participated in the study.

\section{Discuss this article}

Contribute and read comments about this article on the Discussion Forum: http://www.rcgp.org.uk/bjgp-discuss

\section{REFERENCES}

1. Peat G, McCarney R, Croft P. Knee pain and osteoarthritis in older adults: a review of community burden and current use of primary health care. Ann Rheum Dis 2001; 60(2): 91-97.

2. Gignac MA, Davis AM, Hawker G, et al. 'What do you expect? you're just getting older': a comparison of perceived osteoarthritis-related and aging-related health experiences in middle- and older-age adults. Arthritis Rheum 2006; 55(6): 905-12. 
3. Sanders C, Donovan JL, Dieppe PA. The significance and consequences of having painful and disabled joints in older age: coexisting accounts of normal and disrupted biographies. Sociol Health Illn 2002; 24: 227-253.

4. Ehrlich GE. The rise of osteoarthritis. Bull World Health Organ 2003; 81(9): 630

5. Dieppe PA. Osteoarthritis: time to shift the paradigm. BMJ 1999; 318(7194): 1299-1300.

6. Woolf AD, European Union of Medical Specialists Section of Rheumatology/European Board of Rheumatology. Healthcare services for those with musculoskeletal conditions: a rheumatology service. Recommendations of the European Union of Medical Specialists section of Rheumatology/European Board of Rheumatology 2006. Ann Rheum Dis 2007; 66(3): 293-301.

7. Davis GC, Hiemenz ML, White TL. Barriers to managing chronic pain of older adults with arthritis. J Nurs Scholarsh 2002; 34(2): 121-126.

8. Hendry M, Williams NH, Markland D, et al. Why should we exercise when our knees hurt? A qualitative study of primary care patients with osteoarthritis of the knee. Fam Pract 2006; 23(5): 558-567.

9. Blaxter M. Health and lifestyle. London: Routledge, 1990.

10. Richardson JC, Ong BN, Sim J. Is chronic widespread pain biographically disruptive? Soc Sci Med 2006; 63(6): 1573-1585.

11. Jolanki O. Moral argumentation in talk about health and old age. Health 2004; 8(4): 483-503.

12. Calnan M, Wainwright D, O'Neill C, et al. Making sense of aches and pains. Fam Pract 2006; 23(1): 91-105.

13. Ross MM, Carswell A, Hing M, et al. Seniors' decision making about pain management. J Adv Nurs 2001; 35(3): 442.

14. Turner AP, Barlow JH, Buszewicz M, et al. Beliefs about the causes of osteoarthritis among primary care patients. Arthritis Rheum 2007; 57(2): 267-271.
15. Tulle E. The ageing body and the ontology of ageing: athletic competence in later life. Body \& Society 2008; 14(3): 1-19.

16. Donovan JL, Blake DR. Qualitative study of interpretation of reassurance among patients attending rheumatology clinics: 'just a touch of arthritis, doctor?'. BMJ 2000; 320(7234): 541-544.

17. Blomqvist K, Edelberg A. Living with persistent pain: experiences of older people receiving home care. J Adv Nurs 2002; 40(3): 297-306.

18. Victor CR, Ross F, Axford J. Capturing lay perspectives in a randomized control trial of a health promotion intervention for people with osteoarthritis of the knee. J Eval Clin Pract 2004; 10(1): 63-70.

19. Bury M. Chronic illness as biographical disruption. Sociol Health Illn 1982; 4(2): 167-182.

20. Lansbury G. Chronic pain management: a qualitative study of elderly people's preferred coping strategies and barriers to management. Disabil Rehabil 2000; 22(1-2): 2-14.

21. Der Ananian C, Wilcox S, Saunders R, et al. Factors that influence exercise among adults with arthritis in three activity levels. Prev Chronic Dis 2006; 3(3): A81.

22. Sofaer-Bennett B, Holloway I, Moore A, et al. Perseverance by older people in their management of chronic pain: a qualitative study. Pain Med 2007; 8(3): 271-280.

23. Cedraschi C, Robert J, Perrin E, et al. The role of congruence between patient and therapist in chronic low back pain patients. J Manip Physiol Ther 1996; 19(4): 244-249.

24. Rogers A, Lee V, Kennedy A. Continuity and change?: Exploring reactions to a guided self-management intervention in a randomised controlled trial for IBS with reference to prior experience of managing a long term condition. Trials 2007; 8: 6 .

25. Rollnick R, Butler C, McCambridge J, et al. Consultations about changing behaviour. BMJ 2005; 331(7522): 961-963 